While parent's understanding of the general relationship

between parents and children cannot tell us everything

that a parent will do in a specific situation, it is

an important indicator.

\title{
The Cognitive Structure of Parenthood: Designing a Descriptive Measure
}

\section{Carolyn Moore Newberger}

Parenthood is often thought of as a natural or instinctive process. With the birth of a baby, the parent is expected somehow to be fully equipped to raise a child with love and skill. Yet increasing awareness of the magnitude of such problems as child abuse and neglect, emotional disturbances in children, and adolescent pregnancies and runaways has forced the realization that parenthood is at best a difficult process and at worst an experience of failure and a source of stress and disability for many families. In response to this awareness, many programs and approaches for aiding parents in their tasks and roles are being offered. But despite the proliferation of childrearing literature and parent education enterprises, knowledge of the fundamental processes that under-

I thank the following for their contributions to my thinking, for access to clinical and other resources, for technical assistance, and for editorial guidance: Susan Baker, Susan Hyde, Nancy Jacobs, Lawrence Kohlberg, Melvin Levine, Marcus Lieberman, Eli Newberger, David Pillemer, Julius Richmond, Robert Selman, Bessie Sperry, Terry Tivnan, and Regina Yando. Partial support for this work came from grants provided by the Radcliffe Institute, the Danforth Foundation, and the Administration for Children, Youth, and Families, DHEW grant number OCD-CB-141. 
lie the parent-child relationship, and upon which intervention should be based, is limited.

\section{Approaches to the Study of Parenthood}

Much of the research on parenthood has investigated the relationship between parental caretaking attitudes and parental behavior. Parental attitudes, however, have been found to be poor predictors of parental behavior (Berg, 1976) or of children's development and behavior (Becker and Krug, 1965). The relation between social and environmental stresses on parents and parental behavior has been an important direction for research on parenthood (Garbarino, 1976; E. Newberger and others, 1977). While certain stress factors have been found to be associated with parental dysfunction, predictions of parental disability or action cannot be based upon them to any great extent (Daniel and others, 1978). In contrast, the importance of parental understanding of the child has been noted consistently in both research and clinical literature (Berg, 1976; McGillicuddy-De Lisi, Sigel, and Johnson, 1979; Sameroff, 1975). Clinically, parents with serious difficulties with the parental role are frequently described as lacking empathy with their children (Aldridge, Cautley, and Lichstein, 1974; Spinetta and Rigler, 1972).

Differences in understanding of their children were also noted in clinical interviews I conducted with parents, some of whom had abused a child. In particular, parents with especially troubled relationships with their children were frequently unable to perceive their children as having needs and rights of their own. Other parents understood their children as separate individuals but in a rather stereotyped way. Still other parents reasoned about their children as distinct and unique individuals. The patterns of parental thinking that I observed appeared to parallel descriptions of different cognitive-structural stages in children's understanding of others' perspectives as they have been described by cognitive-developmental investigators (Kohlberg, 1969; Piaget, 1950; Selman, forthcoming). These investigators have described children's conceptions of others as progressing from an egocentric focus on the self's perspectives to an increasingly complex and comprehensive awareness of the perspectives and intentions of others.

\section{Parental Conceptions and Social-Cognitive Developmental Theory}

The parent's conceptions of the child and of the parental role seem logically to represent cognitive structure in parenthood. In cogni- 
tive-developmental research, cognitive structure refers to stable patterns of thought that define how an individual makes sense out of experience and organizes his or her responses to it. Structure defines the capacity of the individual to acknowledge and to utilize what is in the environment. Through interaction with the environment, the structure of thinking undergoes a process of transformation through sequential developmental stages. At the least mature stages, the individual can take into account only limited aspects of experience and can think about that experience only in limited ways. As the individual moves into more mature stages of thinking, a more comprehensive range of information can be acknowledged and utilized. Thinking becomes increasingly flexible as the individual becomes able to consider solutions to problems from various perspectives and in greater depth.

As applied to parenthood, it appeared that cognitive structure might be revealed in the organization of reasoning about the child's experiences, the effects of experience on the child, and justice and responsibility in the parental role. Based on these observations and ideas, a clinical study evolved to begin to define the parameters of Parental Awareness (as the construct has been named [C. Newberger, 1977]). Parental Awareness can be thought of as an organized knowledge system with which the parent makes sense out of the child's responses and behavior and formulates policies to guide parental action. At successive stages of Parental Awareness, parents would theoretically be aware of deeper aspects of the child and of more complex interactions between the child and themselves. With greater awareness greater flexibility would evolve in sorting through the dimensions and arriving at resolutions of the tasks of parenthood. Parental Awareness differs from parental attitudes in the level of analysis of thought, representing an underlying structure of concepts of people and roles rather than a more superficial point of view about specific caretaking behaviors and styles. As an example, let us consider how the reasoning underlying a statement of belief about a parental response reveals very different ways of understanding the child and the parental role. Two parents might both believe that mothers can get very upset when they cannot get their babies to stop crying. One parent may reason that mothers get upset because crying is unpleasant to hear and they feel like bad parents if they cannot get the baby to stop. The other parent may reason that mothers get upset because they feel the child is in distress and they do not understand what is wrong in order to help the child. One parent thinks solely within the framework of his or her own needs; the other can consider the child's needs as well.

The parameters of parental cognition are thought to include two dimensions - a perspective-taking dimension (that is, how the parent 
conceptualizes the child and the child's experience from the child's point of view) and a moral dimension (concepts of rights and responsibilities of the self in relation to the child). Kohlberg (1969) describes the area of morality as "the area of conflicting claims of selves" (p. 398). Parental action is to a great extent a process of negotiating conflicting claims. The introduction into a family of each new member brings new demands and a necessary redistribution of finite physical and emotional resources. Many of the issues with which parents must deal directly involve areas of conflicting claims, such as resolving conflict between family members, changing children's behavior, and meeting needs. The needs and claims of the child come in conflict with those of the parent or siblings, yet the parent must make decisions about what he or she ought to do-decisions that may effect the parent's own resources or contradict the child's will.

\section{Building a Measure of Parental Conceptions}

In order to define the parameters of a construct of Parental Awareness, one must move from clinical impressions and logical analysis to the systematic collection and analysis of data. For this work, the format of a semi-structured reflective interview was chosen because it permits both a standard set of questions to be asked and elaboration and expansion by the respondent using the respondent's own words and logic. The interviewer can be a facilitator and a prober, pushing for clarification of ideas and for the reasons behind answers to questions. It is in the reasons for a parent's opinions and beliefs that the deeper structures of awareness are thought to be revealed.

To construct the interview, a set of issues of parenthood was identified from which questions could be drawn. Each issue presented the parent with a task that had to be solved. Conceptions were derived from the reasoning used to address the task. A conception related to how a parent would think about the child or about acting toward the child when confronted with decision making concerning the child. The issues for the Parental Awareness interview were drawn from clinical experience with parents and from literature on child rearing and parent education (Gordon, 1975; Group for the Advancement of Psychiatry, 1973; Morris, 1977). In order to develop questions that would relate meaningfully to natural parental experience and functioning, as well as permitting the expression of deeper structures of thought, the issues covered a broad range of parental tasks that were assumed to be usual and critical. The issues are as follows:

1. Identifying influences on development and behavior (elements in the child, the environment, and in their interaction that effect the child's behavior and development). 
2. Understanding subjectivity - thinking and feeling (the nature of the subjective experience of the child and how it is identified).

3. Defining personality (qualities and characteristics that make up personality; defining the ideal child).

4. Establishing and maintaining communication and trust (closeness, reciprocity, and sharing).

5. Resolving conflict (identifying and addressing conflict between parent and child and between child and child).

6. Establishing and maintaining discipline and authority (the reasons and methods for the socialization of children).

7. Meeting needs (defining and addressing needs).

8. Learning and evaluating parenting (how parenting is learned; evaluating parental performance).

To elicit parental reasoning on these issues, at least two questions pertaining to each issue were asked. The interview used both direct personal questions and questions about hypothetical dilemmas. On the one hand, questions such as the following directly address the issue of resolving conflict between parent and child: What do you find hardest to put up with with your child? Why is that? How do you handle it? Why? How does it seem to work out? On the other hand, a hypothetical dilemma about a working mother also explores the issue of conflict resolution. The story describes the predicament of a mother with a tenyear-old daughter who is unhappy staying home. When she gets a parttime job and is much more satisfied with her life, her daughter is unhappy because her mother is not home every day the way her friends' mothers are. Questions following the reading of the dilemma probed the parents' understanding of the child's thoughts and feelings and how the conflicting claims between parent and child should be resolved.

The next step in the development of a measure of Parental Awareness was to interview parents. A basic outline for levels of Parental Awareness had been logically constructed beforehand. However, interview data were necessary, both to verify that reasoning could be ordered into a sequence of levels and to define the parameters of the construct more adequately.

Fifty-one parents from a broad cross-section of social and family backgrounds were interviewed. These parents were selected from an outpatient clinic at a large urban pediatric hospital and from neighboring middle-class suburbs. Participants were selected so as to include both black and white fathers and mothers at all social class levels as defined by the Hollingshead (1965) two-factor index of social scale. Families of various sizes were represented, with children of all ages.

An analysis of the interviews revealed that parental conceptions could be ordered hierarchically into four increasingly comprehensive 
and psychologically oriented levels. Within individual interviews, thinking was relatively consistent within and across the issues. The levels of Parental Awareness are briefly described as follows:

Level 1. Egoistic orientation: The parent understands the child as a projection of his or her own experience, and the parental role is organized around parental wants and needs only.

Level 2. Conventional orientation: The child is understood in terms of externally derived (tradition, culture, authority) definitions and explanations of children. The parental role is organized around socially-defined notions of correct practices and responsibilities.

Level 3. Subjective-individualistic orientation: The child is viewed as a unique individual who is understood through the parent-child relationship rather than by external definitions of children. The parental role is organized around identifying and meeting the needs of this child rather than as the fulfillment of predetermined role obligations.

Level 4. Process or interactional orientation: The parent understands the child as a complex and changing psychological selfsystem. The parent, as well as the child, grows in his role, and the parent recognizes that the relationship and the role are built not only on meeting the child's needs but also on finding ways of balancing his or her own needs and the child's so that each can be responsibly met.

From the interview data and analysis a scoring manual was developed that includes instructions for administering the interview and procedures for scoring. It offers detailed descriptions and illustrations of the characteristics of thinking about each issue at each level.

\section{Examples of Parental Reasoning}

In order to provide a sense of what parental reasoning is like, examples from the manual follow for the issue "Establishing and Maintaining Discipline and Authority." The task to be resolved for this issue is to define the direction development should take and to formulate policies for guiding behavior in that direction. The issue, then, has two aspects - reasons for changing behavior and methods by which behavior is changed. The examples that follow illustrate the second aspect. 
For parents in Level 1, reasoning methods are chosen because they are successful in changing behavior the parents find undesirable. The criterion for success is suppression of the behavior, not change in the motives of the child.

\section{What do you rely on most to get your children to mind you?}

Threatening them with a spoon. I have one of those spoons with the little holes, to strain peas and things, so I take that, and I say, "If you don't be good, I am going to beat you with it." And they usually behave when they see it. I don't use it, but when they see it, they usually behave.

\section{How does that seem to work?}

They do mind, up to a certain point, and then they say, "Mommy is not going to spank me," so I will start all over again.

Why do you use that method?

It seems to be about the only method that works.

Do you think it is the best way?

Well, no, but I don't know of any other way that works as well.

The reason for discipline and authority at Level 2 is not just to change behavior but to instill standards and values that will guide the child's action in the future. Therefore, the child's understanding of the reasons for punishment is considered central. The parent explains why what the child is doing is wrong in order to ensure the inclusion of his or her standards into the child's developing value system.

What do you rely on most to get your children to do what you want them to and not to do what you don't want them to?

We explain everything and explain what's good and what's not good and we tell them, we preface, "This is good," and go on to explain why, and he can make a decision as to whether he is going to go along with it or not, and then we will explain and try to reinforce our ideas.

Why is explaining important?

So they will know themselves what is right and wrong.

At Level 3, the parent reasons that behavior has a cause and that, in order to change behavior, its cause, rather than its manifesta- 
tion, must be addressed. The why the parent focuses on at Level 3 is not just the parent's why but also the child's why. At this level, the parent appeals to the effect of the child's action on others, not just the rightness or wrongness of an act.

Let's get back to the subject of discipline. What do you feel is the best way to get a child to mind you?

Talking.

Why is that the best way?

Because first of all, you ask questions, and you find out why they did it, and they tell you, "I broke it because you weren't paying any attention to me." So you find out, "What attention did you want me to pay? I was busy too. After I finish this, then we will sit down, and we will have this big long talk about anything you want to talk about, play any game you want to." Meanwhile, I am finding out, like, "If it is just I felt like breaking it, okay, I just felt like hitting you right now, so how about if I do that? No? Why not?"'Because if you hit me it will hurt." "You hurt me by breaking my vase." I'll handle it like that.

At Level 4, the child is conceptualized developmentally, and the parent believes that certain physical and emotional needs and capabilities must be addressed when they are developmentally relevant in order for other kinds of growth to take place. The focus is not only on the directly underlying explanation or motivation, as in Level 3 , but also on issues of the larger developmental and relationship process in which the issue of discipline and authority are understood to be embedded.

What do you do to get Steven to mind you?

It depends on Steven. What he seems to be asking for at different times in his life. Right now, he's been testing me a lot. He seems to be asking for controls.

\section{What do you mean?}

Children test you to see how much they can get, how much freedom they can get, and to know their boundaries. Yet it is a pull both ways. Steven is trying to test me, plus he wants my comfort and attention and concern. I think if I do control him, he knows I am concerned. Deep down inside he knows that it is for his own good. He can still want something and know that it is dangerous and be grateful at some level to a person for telling them is it for their own good not to do that. 
When ten of the fifty-one parental interviews were scored by independent raters following manual construction, a Pearson correlation (Winer, 1971) between the two raters of .96 was obtained. As the manual was constructed from the interviews and several of the interview responses were found as examples in the manual, such a correlation is likely to be artificially high. In a recent study of an independent sample of parents (Cook, 1979), the manual was found to discriminate among parents, and the reliability between independent raters was .88 .

\section{The Nature of Parental Conceptions: Stages or Childrearing Attitudes?}

The next question in the present analysis is whether the Parental Awareness construct represents a hierarchy of levels of understanding rather than just differing adult values and childrearing attitudes. But how are hierarchical levels determined? In cognitive-developmental theory, a developmental sequence is characterized by increasing adequacy of understanding. As discussed earlier, in each successive level the individual's knowledge system contains an increased amount of relevant data from the environment and the ability to use that data in more flexible and adaptive ways. Validation of the Parental Awareness construct, then, involves evaluating whether the levels represent stable knowledge systems of increasing complexity and flexibility that unfold in a developmental sequence. Formal validation awaits a new sample on which the hypotheses of structure and development can be tested. But as an initial step, one can generate hypotheses for further testing from patterns that emerge in the data at hand.

In cognitive-developmental research, several criteria have been established for validating a cognitive-developmental stage sequence. The first criterion is that each stage must be qualitatively different from the other stages with each successive stage building from rather than discarding the previous stage. The levels of Parental Awareness appear to describe qualitative differences in parental reasoning. For example, the shift from the Level 2 awareness of the child as a type who is understood from the perspective of the conventional wisdom about children to the Level 3 awareness of the child as a unique individual is more than the adding of unique individual characteristics on to character type characteristics. It represents a qualitative reorientation in how children are known and understood.

And yet those questions that the child shares with other children are not lost; rather, they are subsumed within a more comprehensive system of knowledge about the child. The child is understood not only in reference to what children are like in general but also in reference to 
how he or she is different and unique. This provides the parent with a more flexible set of concepts with which to resolve issues in the parental role. If a young child walks without looking into a busy street, the parent might respond with a swat on the bottom, the laying down of rules, and a Level 2 rationale: "Children musn't do that, or they'll get hurt." If, on the other hand, the child has a fear of the dark, a parent with Level 3 awareness can address the problem with sensitivity to this particular child's responses, feelings, and fantasies. For a problem with an individual emotional basis, Level 3 awareness would be the minimum necessary to probe the meaning of the symptom and to address its cause.

The second criterion, the concept of structure in developmental stage theory, refers to stable patterns of thought that are applied consistently across different aspects of experience. As each of the issues in the Parental Awareness interview elicits thinking about different tasks of parenthood, consistent reasoning across issues would suggest an underlying structure to that reasoning. An analysis of response consistency within individual interviews reveals that responses are consistent from issue to issue. Further, reasoning is consistent between the personal what do you think questions and the more action-oriented what would you do questions posed by the dilemmas. Out of an average of twenty-two scorable responses on an individual interview, a mean of sixteen responses are scored at one level (with a standard deviation of 3.7). A mean of five responses are scored at a second adjacent level (with a standard deviation of 3.6) and a mean of one response is scored at a third level (with a standard deviation of 1.8). Parental reasoning appears, then, to be organized primarily at one dominant level, with some thinking at the level above or below.

The third criterion, validation of an invariant developmental sequence, is especially complex. We have some preliminary evidence that Parental Awareness levels represent a developmental sequence that proceeds from lower to higher levels. This evidence derives from two cross-sectional analyses, one of parents with differing years of parental experience and the other of children of different ages. In the parental analysis, a relationship was found between years of parental experience and parental reasoning. When parents with the same number of children are compared with each other, parents with older children reason at higher levels than parents with younger children.

Evidence for developmental sequence in the reasoning of children was also sought because children experience the child side of the parent-child relationship and their concepts of parenthood must be in the process of development throughout their early lives. Sixteen children between the ages of seven and seventeen were administered the Parental Awareness interview as well as a standardized test of verbal 
intelligence, the Peabody Picture Vocabulary Test. The interview was revised so that the personal questions were phrased to read, "If you were a parent ..." The hypothetical dilemmas remained the same. In the children's interviews the Parental Awareness levels were found to be strongly related to age, further suggesting that the levels represent a developmental sequence. None of the children, however, achieved Level 4 reasoning, although many parents did. Although concepts relating to issues of parenthood appear to develop sequentially commencing in childhood, there may be experiences particular to the parental role that are necessary (although not apparently sufficient) to stimulate thinking at the highest level. Cross-sectional studies provide limited data, however. We need longitudinal studies not only to establish invariant developmental sequence but also to go beyond the issue of sequence to explore how development in parenthood occurs and how it differs from the interpersonal awareness and moral judgment applied in other interpersonal domains.

The fourth criterion is that developmental stages capture coherent systems of universally characteristic thought. The collection of extensive cross-cultural data would provide the best evidence to establish whether a developmental stage sequence describes universal characteristics of reasoning. Within a more limited population with differing patterns, however, some sense of universality of a stage construct can be obtained (Cooney and Selman, 1978). For example, if reasoning varied with social class, then it would seem that different Parental Awareness levels might simply represent different theories of childrearing held by different social class groups. If, on the other hand, levels of reasoning were found to be independent of social class, then the possibility that they represent a sequence of increasingly adequate ways of thinking that applies to all parents, whatever their social class affiliation, is enhanced. In this study, correlations were sought between several demographic factors and Parental Awareness level scores. These factors were social class, sex of the parent, and race. None of the correlations were found to differ significantly from chance. Of course, these relationships need to be further examined on other samples. In the children's interviews, verbal I.Q. was not associated significantly with reasoning level. Unfortunately, we were not able to obtain I.Q. estimates for the adults. Other possibly confounding factors such as I.Q., age of parent, and family structure also need to be examined.

\section{Parental Awareness and Parental Functioning}

Even though the work of construct development continues, my clinical interest in the problem of child abuse and neglect led me to conduct a small study to approach a question that in the future must be 
addressed. The question is the relationship of Parental Awareness to parental behavior. In order to investigate that relationship in a very preliminary way, eight families with a recent history of child abuse or neglect were selected from a clinic established to provide treatment for families with dysfunction in the parent-child relationship. Each parent who had abused or neglected a child was matched individually with a parent from the medical clinic who had been a member of the original sample of fifty-one, none of whom had a known history of having abused or neglected a child. Four matching variables were used-social class (using the Hollingshead [1965] two-factor index of social position), ethnic status, number of children, and age of the oldest child.

In seven of the eight matched pairs, the abusive or neglectful parents scored lower on the measure of Parental Awareness than their matched counterparts. A t-test for correlated observations (Siegel, 1956) indicates that the difference between the two groups is highly significant $(t=5.20, p<.01$, two-tailed). These data suggest that the developmental level at which a person organizes his or her awareness of the child and the parental role bears a relationship to parental behavior.

It must be pointed out, however, that not every parent who abused or neglected a child had a very low level of Parental Awareness and not every parent from the original sample of fifty-one had a higher level of awareness. Although the majority of parents in the original sample reasoned at Levels 2 and 3, eleven parents had scores below Level 2 and did not have a clinical history of child abuse. (Of course, this does not mean that they do not have difficulties in the parental role but rather that they did not, as far as is known, manifest their difficulties by abusing or neglecting their children. It is difficult to account for parents who reason at relatively high levels of awareness and mistreat their children or for parents who reason at relatively low levels of awareness and apparently do not mistreat their children.

To increase our understanding of such parents, let us think about the nature of a cognitive stage. A cognitive stage defines what the individual is capable of considering in the environment in order to explain what he or she experiences. A cognitive stage relates to capacity for understanding, not to performance. A person may be capable of understanding at a mature level but may not use that understanding when resolving problems in his or her life. For example, a parent might be able in an interview situation to reason about the tasks of parenthood at a mature level. Yet when struggling under extreme stress, that same parent might become overwhelmed with anger and frustration and behave in a dangerous or destructive way toward his or her child.

It would seem that parents who reason at very low levels of Parental Awareness would be more likely to be inadequate parents. But 
perhaps with strong supports in their lives, such parents would be able to raise their children adequately. Conversely, it would seem that parents who reason at very high levels of awareness would be the most likely to raise their children well. But under extreme stress, even these parents might have serious difficulties in the parental role.

The likely relationship between Parental Awareness level, stresses and strengths in the family environment, and the probability of dysfunction in the parent-child relationship are illustrated in Figure 1.

These relationships are perhaps best illustrated by looking at some clinical examples. Four parents will be presented, two of whom have a history of severely neglecting a child and two of whom do not. Let us first consider two parents who scored at an egocentric level on the Parental Awareness interview. Mrs. Slater has severely neglected her six-year-old son Bobby. Mrs. Brooks does not have a history of dysfunction in the parental role. Both women have high school diplomas and scored almost identically on the Parental Awareness interview (1.16 for Mrs. Slater and 1.17 for Mrs. Brooks). Mrs. Slater is the mother of four children between the ages of twenty-one and six and supports herself and the two younger children on $\$ 4,000$ a year by working in a menial job. In addition, Mrs. Slater is an illegal alien in this country and lives in fear of being discovered. She has moved frequently over the years from one inadequate housing situation to another. She has few friends she can turn to and no man at home. In

Figure 1. Parental Awareness Level and Parent-Child Relationship

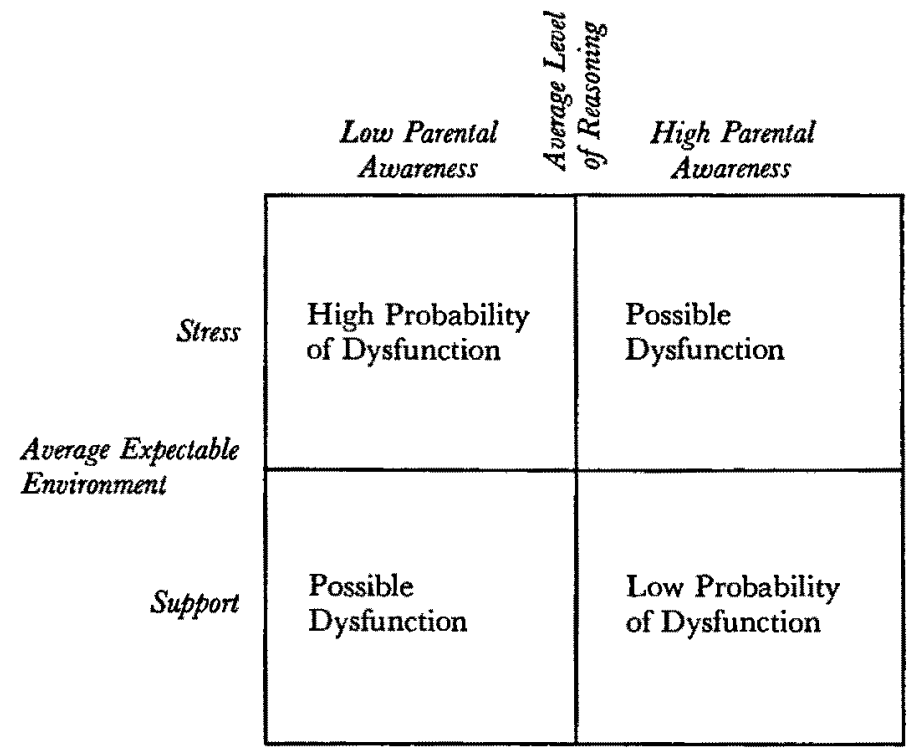


the interview, Mrs. Slater does not seem able to think about her children or her children's needs independently of her own, as the following statements illustrate:

What do you enjoy most about your children?

I enjoyed them when they were small.

Why was that the best?

Because then you can do things for them, they cling to you more, they appreciate what you do for them, and they are more loving and everything, you know. Now that they are grown, they are looking for their own way of life. So I think when they are smaller, they are the best.

Why do they appreciate you when they are small?

In certain ways they show you because small kids, they hug you, and like Bobby is very affectionate, and he would hold you and kiss you, and if you go out and come back, he says, "I am glad you came back," things like that. He is alright.

When her children present her with problems, Mrs. Slater appears to have few conceptual resources for recognizing their developmental needs or for finding ways of changing their behavior. Rather, she sees them as being unchangeable and herself as helpless and gives up.

What do you find the hardest to put up with?

There is no problem with the small kids. The only problem I have is with the big ones, when they want to do things I don't want them to do, and then it upsets me.

What kind of things do they want to do?

They want to go to parties, and you wouldn't want them to go, or you wouldn't want them to do this, and they figure they are old enough to do it, and they sometimes look at what someone else is doing, and they want to do it too, and they get into a lot of trouble. More than a small child.

How do you handle that?

I don't know, I went through different stages. Right now I am in a stage that I just leave them alone. I try to understand that is a different age than when I was in. Before I could not understand it, and it used to worry me, but now $I$ just get 
myself down and say there is no sense fussing and fighting, and $I$ just let them go and try to be cool and calm, because if I fuss and worry about it, it would just upset me more, because if they want to do it, and they figure they want to do it, they are going to do it anyway, so I just leave them alone.

Bobby is a child who has presented Mrs. Slater with problems, and she appeared to be unable to understand or to attend to his needs. He was born prematurely eight years after the next oldest child. Despite his fragility as an infant, he received variable and inadequate medical care because Mrs. Slater was concerned that she might be discovered to be here illegally if she registered for Medicaid. She had no money for private care. Bobby was malnourished in infancy because Mrs. Slater would only use one particular formula, which did not meet his nutritional needs as he got older.

Mrs. Slater seriously infantalized Bobby. He was fed with a bottle until age five and remains extremely infantile. Although she has been urged to permit a psychological assessment of Bobby, Mrs. Slater refuses to have it done. As we could see by her statements above, she feels better when her children are babies and is trying to keep Bobby in the infantile state. As she said in the interview, Bobby is a small kid who holds her and hugs her and kisses her. How remaining a small kid is affecting Bobby is not being considered at Mrs. Slater's level of reasoning.

Mrs. Brooks has no history of extreme parental dysfunction. She has three children between the ages of seven and ten. The children have presented no special problems except for the youngest, who has a minor orthopedic problem. She lives with her husband, a salesman at a small shoe store, and works part-time in a factory. For Mrs. Brooks, childrearing is a frustrating task, a continual struggle against the anarchy of her children. Consider, for example, the following statement:

Can you describe your children for me?

They are always fighting. You can see what they are like. First of all, they are noisy. I don't think that I could stand to have them around me too much all the time. And they are not very orderly, they have the worst room, I can't get them to clean it up.

Her reasoning about how children develop focuses on a Level 1 conception that "they copy their parents. They end up copying their parents or someone they admire." 
What has been the most important influence on you as a parent?

How have you learned to become a parent?

I am a lousy parent really. I could be a better one. I feel I shouldn't have to yell at them and ask them not to do this and that. And they should clean up their rooms. Maybe if I didn't keep my own room a mess, they would clean up theirs. I think about that a lot. So I think parents, in order to make good children, have to set a good example. Like parents expect them to be perfect, but if you're not perfect yourself, if you swear in front of the children, they are going to swear. That is why I think I am not so perfect as a parent, because there are things that I could do or should do and I don't.

As she is not a perfect parent, her children do things they should not. But in finding ways to make her children behave better, Mrs. Brooks is limited severely by her lack of understanding of what goes on inside the child. She can only think in terms of stopping outward behavior, not in terms of stimulating change in the child's values or motivations. She and her children are consequently engaged in an ongoing struggle, and her efforts to change behavior are only temporarily successful.

What do you feel is the best way to get children to mind you?

Well, yelling at them all worked, though once in a while I have to get my belt, and I will use it when they get to the point where they just don't mind me. And I hate that procedure because it takes a lot out of me. But you have to show them. You have to discipline them one way or another. They say spare the rod and spoil the child or something like that.

Do you find that this approach works?

Yes. Why? Well, no one likes to be punished, especially with a belt. I imagine to a child it hurts, and they know you mean business.

Do you think there are better ways?

There are only three ways I can think of, yelling and scolding them, punishing them, and third, taking away something they like, a privilege or an allowance. But where my kids don't get anything like that, I couldn't use that method. I'm always yelling at them, but I punish with a belt as a last resort.

It seems conceivable that Mrs. Brooks could, if sufficiently stressed, abuse or neglect a child. However, there may be supports in 
her life that keep her from such extremes of behavior. Although she berates her husband for not spending more time with their children, he does make a contribution. She's not entirely pleased, however, that they behave better when he is around, as the following statements indicate.

What do you feel children need most from their parents?

Well, they need love. I think children need love from both their parents.

What do you mean by love?

The parents are supposed to keep them well and take them places and do for them and buy for them and spend time with them. I think children need love from both their parents, not one, but both. Like in this case, they get it mostly from me, since I am ruling the suite and they aren't with their father much. When they do see their father, they can do no wrong. My husband doesn't discipline the kids at all, and he leaves everything up to me, which I wish he wouldn't do. I would like for him to scold them or spank them. When he is with the kids, they set a good example, they act good for him. I don't know why.

Although Mr. Brooks was not interviewed, it is possible that he understands his children at a higher level, modifying the effect within the family of his wife's immature understanding.

Another factor that may protect this family is their relatively higher level of income as compared with Mrs. Slater. Their $\$ 10,000$ income is certainly modest, but they are able to avoid the stress of extreme poverty. Indeed, when comparing low scoring parents who have abused or neglected their children with the low scoring parents from the original sample of fifty-one, one finds striking differences in income. The average income for the parents who had abused or neglected a child was approximately half that of the other low scoring parents. Parents in the abuse and neglect sample were also twice as likely to be living alone. This suggests that for parents with immature conceptions of their children and of the parental role, greater social and economic supports may play a role in enabling more adequate functioning. But in the face of greater stress, these families may be particularly vulnerable to extreme dysfunction in the parental role.

In contrast, let us look at two parents with higher levels of reasoning. Both are high school graduates. Of the eight parents in the abuse and neglect sample, Mrs. Morgan had the highest Parental 
Awareness score, 2.75. She has a five-year-old daughter, Ellen, and is divorced. In the interview, as the following example indicates, Mrs. Morgan was aware of Ellen as a person independent of herself and demonstrated Level 3 reasoning as she described her concern to understand and be responsive to Ellen's needs.

\section{What do you think children need most from their parents?}

Love and time, and they need to have their needs considered, that they can't be happy doing what we do and they can't be happy with the things that we want to make them happy. You have to look at them, and if they don't tell you, you have to ask them. You have to try to find out what is going on in their heads. If I feel that I have lost touch with where she is at, I will sit down and talk and say, "What is happening," and "Is everything alright?" And she will tell me. And I ask if anything I am doing is upsetting her or making her angry. And if there is anything wrong, she lets me know, and we just talk about it, and we try to reach an opinion.

Clearly, Mrs. Morgan is sensitive to Ellen's feelings and sees their relationship as an emotional exchange, not just as an exchange of goods and services. She does not feel that she must be a perfect mother but emphasizes the importance of a strong emotional tie. For her, a good parent has a good relationship with his or her child and thinks about the effects of his or her actions on the child: "I try to think about what I am doing; think about what effect it has on her."

Paradoxically, Mrs. Morgan has behaved in a way that has seriously harmed her child. She was taken to court for severely neglecting Ellen. She has refused to have her psychologically evaluated, as was demanded by the court. She has failed to follow up on ophthalmologic care for strabismus, which Ellen has had since birth. How can we explain the extreme discrepancy between Mrs. Morgan's capacity to consider her child's needs and her lack of action on behalf of those needs?

Perhaps some explanation is offered by Mrs. Morgan's own upbringing and recent history. She was raised as the oldest child in a very strict, religious home. Her adolescence was stormy and rebellious, and during her early adulthood, she became a serious abuser of hard drugs. She lived with members of what might be called a drug cult. Even after Ellen's birth, Mrs. Morgan led a nomadic existence, drifting from one place to another with other drug abusers. Mrs. Morgan's mother took her to court because of the neglect of her grandchild and gained custody of Ellen. Currently, Mrs. Morgan and Ellen are living 
with Mrs. Morgan's mother. Mrs. Morgan is in a drug rehabilitation program but has been unable to find a job. The struggle to escape the hold of drugs is excruciating. Mrs. Morgan is on welfare and feels worthless as a mother and as a provider. She is back in the situation of dependency on and overly rigid control by her mother that led her to flee into drugs in the first place. Mrs. Morgan reports a great deal of tension between herself and her mother, and Ellen has developed asthma in this situation. Mrs. Morgan feels overwhelmed and at times becomes so angry and frustrated that she takes out her anger by yelling at or hitting Ellen. At other times she simply cannot cope with responsibility for another and so does not follow up on Ellen's medical care. Clearly, she has a long and difficult struggle ahead of her, if she is to realize in behavior the potential as a parent that is suggested by her reasoning.

Our last example is that of Mrs. Frank, whose score on the Parental Awareness interview was 3.29. She is also separated and is struggling to support herself and her two children, ages two and four, on less than $\$ 5,000$ a year. Mrs. Frank supplements her welfare check with babysitting in her home. She cannot afford a telephone and feels quite isolated and alone. Yet despite her problems, Mrs. Frank is not only able to respond sensitively to her children's needs but also to learn from and grow with her children, as the following statements illustrate.

What do you enjoy most about the children?

I think it is their dispositions that really make it easy for me to care for them. I am not an easygoing person. I'm terribly hard to live with, but both of them are so different. They make me a better person because of themselves.

\section{How is that?}

A lot of times I will hold back my feelings on something and not let it out, and Stacey will come along, and if something makes her mad, she will get mad. Yet with her I can say, "That's okay, you can explode, but now it is time for me to do it." I've become a little more outgoing a little more talkative because I've seen things in them that I couldn't do, that I don't feel I could ever be able to do. Yet seeing that they are not shy and seeing that they are not held back by anything, and if they want to know something, if somebody else is standing there and they see something, they will walk up and ask, "What is going on," or "What is that?" They are not shy at all, and I think by seeing them, I can learn their lesson and teach other people, which I have never been able to do. 
How do you feel about that?

I feel good, I really do. It is not just their learning from me, I am learning from them, also, about my own feelings and what to do about them.

An important difference between Mrs. Frank's and Mrs. Morgan's situations is that Mrs. Frank is emotionally and economically independent. She is making it on her own, and her children are seen as an important part of a process of personal growth that enables her to address her own and her children's needs. Such a process orientation is illustrative of Level 4 reasoning.

Mrs. Frank's struggle to survive at this difficult time, does not, despite her own need for the insights and support her children offer, appear to diminish her capacity to take into consideration their needs as individuals independent of her. Consider, for example, how she handles their relationship with their father, her former husband.

Do they see their father?

Yes, they do, very much. I think more so than before. It is not something I would stop. As far as I'm concerned, we are finished and that's it, but as far as they are concerned, he is their father. I don't allow anyone to put him down, and I don't put him down, even though I'm angry at him because he doesn't give me any money for their support. But I don't feel that should have anything to do with the children. They need their father and need to feel loved by him. And he does still care for them very much. But as far as our relationship with each other, no.

Although one cannot generalize from two case examples, one might speculate that for Mrs. Morgan, the emotional price of drug dependency and withdrawal and of living as a dependent adult in her mother's home is severe and compromises her ability to express consistently in behavior the concern and awareness she articulates toward her child. For Mrs. Frank, however, a high level of Parental Awareness appears to support her ability to function sensitively as a parent (and as a person) in the face of considerable stress.

\section{Directions for Future Research}

Clearly this research is just a beginning, the initial construction of a rationale on which to grow. The next step in this analysis will be construct validation, using a new sample to confirm that the measure discriminates among parents, that parental reasoning shows structural 
consistency and represents a developmental sequence, and that parental awareness levels cannot be reduced to I.Q., social class, ethnicity, or to other possibly confounding variables. Such new data are now in the process of being collected.

The question of parental development might best be addressed with a longitudinal study. An initial issue is why some parents begin parenthood at lower levels than others. As parents are followed over time, perhaps beginning with their first pregnancy, development of reasoning about the child and childrearing choices could be monitored. Within a longitudinal framework, experiences and characteristics that appear to stimulate or to impede parental development could be identified and used to guide intervention. Parental behavior might also be systematically observed and analyzed in a longitudinal study in order to clarify the relationship between parental reasoning and parental action.

A further question for future research is the relationship between Parental Awareness and children's development. Of particular interest would be the relationship between parents' levels of awareness and their children's developing sense of themselves and of others, and ultimately, of their own children. Also of interest and importance is the child's contribution to the parent's conception of the child. When reading the clinical records of the children of the eight parents in the child abuse sample, it is striking to note how high the incidence of morbidity in the neonatal period was. How do prematurity or congenital handicap affect the development of a mature awareness of the child as a person, and how might more mature awareness be fostered under such circumstances? As the child gets older, what is the role of temperament and of temperamental match between parent and child, in the parent's developing awareness of the child and of the parental role?

\section{Implications for Intervention}

Parental reasoning is but one aspect of parental process, but it is an aspect that may be important in parental functioning. Interventions on parental reasoning would be an important supplement to current intervention modalities.

Shure and Spivack (1978) report a program in which mothers are taught to train their children in interpersonal problem solving skills and receive training in interpersonal problem solving skills themselves. They have found that the mothers have become more aware of their own and other's feelings and the effects of their behavior on others. Such encouraging findings suggest that the development of Parental Awareness, although assessed with a measure other than the one presented in 
the Shure and Spivack study, can and does take place with thoughtful and carefully implemented intervention.

Two intervention modalities might be considered-family intervention and parent group intervention. Family intervention would provide interpersonal experiences with family members, such as mutual problem solving or discussions of feelings and perspectives about family problems and family issues.

In Parental Awareness groups, perhaps in addition to a traditional emphasis on group support and child development information, hypothetical parent-child conflict dilemmas could be presented to focus and stimulate discussion. The dilemmas would present tasks to be resolved concerning such issues as trust, authority, conflict resolution, and meeting needs. Discussion of hypothetical situations might lead to sharing and discussion of parents' personal dilemmas in their own parent-child relationships. Through the process of reasoning about tasks in the parental role and through hearing and considering reasoning at higher levels than their own, development of more mature conceptions might be stimulated.

These suggestions for future research and clinical intervention are not meant to be exhaustive. Rather, they suggest some of the possibilities for this approach, both for developing greater understanding of the nature and role of reasoning in parenthood and for applying greater knowledge to the understanding and amelioration of problems in the parent-child relationship.

The value of the cognitive-developmental approach to clinical practice would not be to provide an alternative explanation for understanding and intervening in parental functioning. More correctly, it would supplement sociological, psychological, and educational approaches and insights, enabling a more comprehensive understanding of parental development and process and offering new insights into the formation of the enduring parent-child relationship.

\section{References}

Aldridge, M, Cautley, P., and Lichstein, D. Guidelines for Placement Workers. Madison: University of Wisconsin Center for Social Service, 1974.

Becker, W., and Krug, R. "The Parent Attitude Research Instrument-a Research Review." Child Development, 1965, 36, 329-365.

Berg, P. "Parental Expectations and Attitudes in Child Abusing Families." Dissertation Abstracts International, 1976, 37 (4), 1889-B.

Bruss-Saunders, E. "The Development of Children's Understanding of Parent-Child Relationships." Unpublished manuscript, Harvard-Judge Baker Social Reasoning Project, Harvard University, 1977.

Cook, S. "Parental Conceptions of Children and Childrearing: A Study of Rural Maine Parents." Unpublished master's thesis, Tufts University, 1979. 
Cooney, E., and Selman, R. "Children's Use of Social Conceptions: Toward a Dynamic Model of Social Cognition." In W. Damon (Ed.), New Directions for Child Development: Social Cognition, no. 1. San Francisco: Jossey-Bass, 1978.

Daniel, J., and others. "Child Abuse Screening: Implications of the Limited Predictive Power of Abuse Discriminants from a Controlled Family Study of Pediatric Social Illness." International Journal of Child Abuse and Neglect, 1978, 2, 247-259.

Feil, L., and Sameroff, A. "Mother's Conception of Child Development: Socioeconomic Status, Cross-Cultural and Parity Comparisons." Paper presented at 87 th annual convention of the American Psychological Association, New York, September 1979.

Garbarino, J. "A Preliminary Study of Some Ecological Correlates of Child Abuse: The Impact of Socioeconomic Stress on Mothers." Child Development, 1976, 47 (1), 178-185.

Gordon, T. Parent Effectiveness Training. New York: New American Library, 1975.

Group for the Advancement of Psychiatry. The Joys and Sorrows of Parenthood. New York: Scribner's, 1973.

Hollingshead, A. Two-Factor Index of Social Position. New Haven: Yale University Press, 1965.

Kohlberg, L. "Stage and Sequence: the Cognitive-Developmental Approach to Socialization." In D. Goslin (Ed.), Handbook of Socialization Theory and Research. Chicago: Rand McNally, 1969.

McGillicuddy-De Lisi, A., Sigel, I., and Johnson, J. "The Family as a System of Mutual Influences: Parental Beliefs, Distancing Behaviors, and Children's Representational Thinking." In M. Lewis and L. Rosenblum (Eds.), The Child and Its Family. New York: Plenum, 1979.

Morris, L. (Ed.). Education for Parenthood: A Program, Curriculum, and Evaluation Guide. Publication No. (OHDS) 77-30125. Washington, D.C.: Department of Health, Education and Welfare, 1977.

Newberger, C. "Parental Conceptions of Children and Childrearing: A StructuralDevelopmental Analysis." Unpublished doctoral dissertation, Harvard University, 1977.

Newberger, E., and others. "Pediatric Social Mlness: Toward an Etiologic Classification." Pediatrics, 1977, 60, 178-185.

Piaget, J. The Moral Judgment of the Child. New York: Harcourt Press, 1950.

Sameroff, A. "The Mother's Conception of the Child." Paper presented at 3rd biennial conference of the International Society for the Study of Behavioural Development, Guildford, Surrey, England, July 1975.

Schaefer, E., and Bell, R. "Development of a Parental Attitude Research Instrument." Child Development, 1958, 29 (3), 339-361.

Selman, R. The Growth of Intetpersonal Understanding: Developmental and Clinical Analyses. New York: Academic Press, forthcoming.

Shure, M. B., and Spivak, G. Problem-Solving Techniques in Childrearing. San Francisco: Jossey-Bass, 1978.

Siegel, S. Nonparametric Methods for the Behavioral Sciences. New York: McGraw-Hill, 1956.

Spinetta, J., and Rigler, D. "The Child Abusing Parent: a Psychological Review." Psychological Bulletin, 1972, 77, 296-304.

Winer, B. Statistical Principles in Experimental Design. (2nd ed.) New York: McGraw-Hill, 1971.

Carolyn Moore Newberger is staff psychologist at the Judge

Baker Guidance Center, Boston, and on the faculty of the

Harvard Medical School. 
